\title{
Planning of a Smart Local Energy Community: The Case of Berchidda Municipality (Italy)
}

\author{
Emilio Ghiani ${ }^{1, *} \mathbb{C}$, Andrea Giordano ${ }^{1}$, Andrea Nieddu ${ }^{2}$, Luca Rosetti ${ }^{3}$ and Fabrizio Pilo ${ }^{1}$ \\ 1 Department of Electrical \& Electronic Engineering, University of Cagliari Piazza d'Armi, \\ 09123 Cagliari, Italy; giordano.andrea91@gmail.com (A.G.); pilo@diee.unica.it (F.P.) \\ 2 Berchidda Municipality (Italy), Piazza del Popolo, 5, 07022 Berchidda, Italy; sindaco@comune.berchidda.ot.it \\ 3 Consorzio S.I.E.S.-Sviluppo Integrato per le Energie Sostenibili, Via Caboni 10, 09123 Cagliari, Italy; \\ rosetti@consorziosies.it \\ * Correspondence: emilio.ghiani@unica.it; Tel.:+39-070-675-5872
}

Received: 21 August 2019; Accepted: 4 December 2019; Published: 5 December 2019

\begin{abstract}
Recent strategic policies and regulations dealing with market liberalization and decarbonization plans, such as the European directives contained in the recent EU Clean Energy for All Europeans Package, are seeking to promote new roles for citizens in the management of the self-produced renewable energy and the development of local energy markets. In this context, this paper aims at presenting the planning actions for the transition of the current passive distribution system of the Municipality of Berchidda (Italy) towards a smart local energy community. This planning study represents the first stage of a development action financed by the Sardinian Region, whose Regional Energetic and Environmental Plan identifies the Municipality of Berchidda as a priority area to focus the experimental actions for innovative smart grids and intelligent energy management. The project, named "Berchidda Energy 4.0", focuses on increasing the energy efficiency of the community by boosting local renewable generation production and maximizing its self-consumption, also with the support of storage systems, as well as increasing the active involvement of the consumers that will be equipped with a smart home automation system for demand response applications.
\end{abstract}

Keywords: local energy community; socio-technical systems; smart grid; renewable energy sources; smart building automation

\section{Introduction}

Nowadays, energy systems across the globe are going through a radical transformation as a result of technological changes that follow the persisting growth of variable distributed renewable generation-mostly in power distribution networks-that is gradually changing the operating conditions of the entire power system, requiring coordination among transmission grids and distribution networks management. In particular, the power distribution sector is foreseen to be the more involved in the evolution of the power system towards future smart grid scenarios, in which active networks will be more intelligently capable of integrating renewable energy sources (RES), demand side response (DSR), and energy storage systems (ESS). The transition towards smart distribution networks (SDN) will require the implementation of new concepts with a novel electrical system structure as well as the addition of novel types of control systems and equipment able to manage bidirectional power flows, according to the new policy and regulatory frameworks [1].

The ever-increasing number of distributed energy resources (DERs) diffusion requires the reorganization of the management of energy systems according to the smart grid paradigm [2]. In fact, due to strategic policies and regulations, such as market liberalization and decarbonization plans, which are stimulating the decommissioning of large fossil-fuel-powered power plants, and the 
adoption of local measures for grid architectures and operation [3] able to better integrate the renewable sources deployment [4], the management of the power system is moving from centralized towards to decentralized models. Therefore, the future power system requires the exploitation of the flexibility offered by all the involved parties in order to obtain a reliable and cost-effective power supply. However, a paradigmatic change of the power system operation from a top-down [5] to a bottom-up approach [6] implies a shift of responsibilities from centralized authorities towards decentralized entities, which encourage the interaction of all the grid users.

In this context, with the aim to guarantee an economical, secure, reliable, and sustainable electric supply, novel approaches that enable the active participation of electricity users have been proposed in the recent literature. In [7], a theoretical framework was provided to guide the development of community microgrids with renewable energy. In the paper, four types of microgrid ownership and control structure were studied to explain the best conditions for public and/or private financial ownership and governance. In [8], the authors examined the policy and practice of community renewables in the UK and defined the meaning of the term "community renewables". Article [9] identifies demand side management as one particular issue, along with the need for social, political, and regulatory plans for the energy autonomy in sustainable communities built with the deployment of a range of small-scale renewable energy systems. The research in [10] investigates the social aspects of thirteen local community energy initiatives in the North of the Netherlands; the social issue is crucial for the effective development of an energy community.

Currently, several reference models for the development of a Local Energy Community (LEC) exist since the relevant regulatory framework is still evolving worldwide. In Europe, the recent directives contained in the Clean Energy Package (CEP) [11] are seeking to promote new roles for citizens who produce and use energy by promoting local energy markets and introducing the concept of energy communities. Currently, there is a proliferation of LEC definitions, but there is still a lack of effective full implementation of the principles contained in the EU directives [12,13]. Table 1 summarizes the current definition regarding local energy communities as provided by the CEP, which defines the Renewable Energy Community (REC), which is contained in the recast Renewables Directive [12], and Citizen Energy Community (CEC) which is contained in the recast Electricity Directive [13]. It has to be underlined that the term "Local Energy Community" is not used in the directives of the CEP, but the authors believe that the use of this term, in this specific case, with limited geographic extension of the community under study, is not misleading, and it will be adopted in the rest of the paper.

Table 1. Comparison of the "Renewable Energy" and "Citizen Energy" Community concepts.

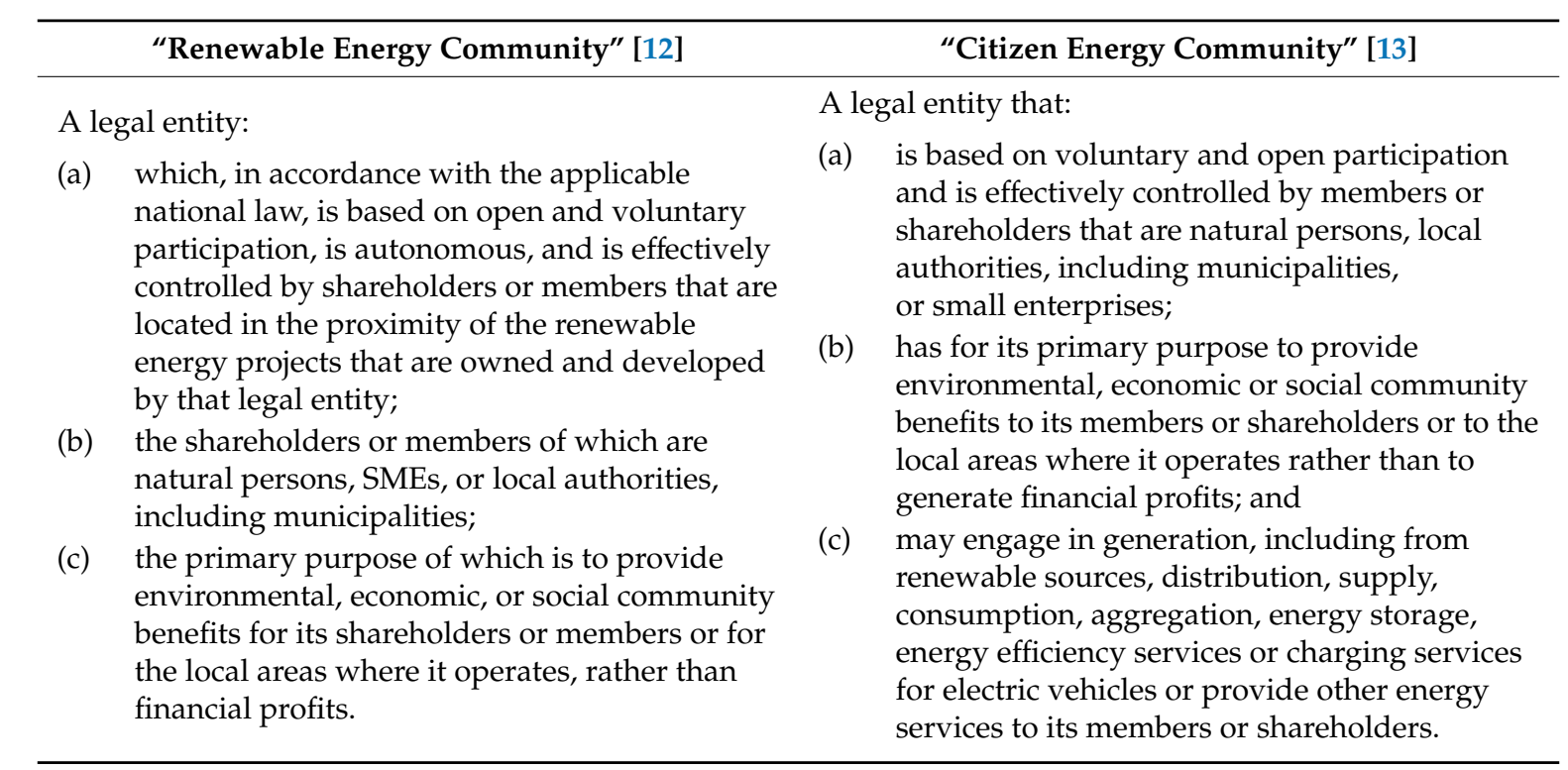


The directive further states that RECs shall be entitled to produce, consume, store, and sell renewable energy, including through renewable power purchase agreements [13]. Despite their differences, the two types of energy communities have major commonalities [14]. In particular they

- Require a legal entity as a community umbrella,

- Have to be inclusive and open to new participants,

- Should be primarily value-driven rather than focusing on financial profits,

- Require a specific governance (e.g., effective control by certain participants),

- Should be collective actions.

The application of the directives contained in CEP implies a strong obligation for the Member States to promote the development of the energy communities. According to this outlook, the paper describes in detail the ideas and the strategies behind the "Berchidda Energy 4.0" project, considering the current status of the electricity distribution system and its evolution towards a LEC, which has all the features defined in the directives, aimed at maximizing the energy independence of the Berchidda community whilst also reducing carbon emissions.

\section{The Energy Community as a Socio-Technical System}

An energy community can be seen as a distinctive Socio-Technical System (STS), where the social and technical aspects of an organization (i.e., a community of people) are strictly interrelated. Within the energy community, a high level of interaction between complex infrastructures and human behavior is predictable. For this reason, in order to successfully manage the transition of the energy system towards an energy community, the social involvement, acceptance, and support of citizens is essential [15].

Energy communities are based on the massive deployment of distributed generation (DG), which require the development of new infrastructures, investments, land-use decision, etc., that are issues with socio-political implications.

In this LEC project, the opportunity will be provided for citizens to be actively engaged in the community and be an active part of the local energy system development. The LEC members, instead of being considered as mere electricity consumers, will be able to assume a number of different roles within the future power distribution and generation system since they are able to influence the way in which the energy is produced and exchanged within the community [15]. However, explained by Seidl et al. in [16], this catches the opportunities offered by integrated renewable sources, combined heat and power production, various methods of energy conversion and storage, and active demand-side management, and there is the need of social acceptance and consciousness.

The social acceptance is generally quite relevant, but, in this specific case, it is expected that the citizens will accept the proposed actions for the transition towards an energy community. In fact, the implementation of the plan is under the responsibility of the public administration rather than leaning exclusively on individual participants for the future energy community. In the Berchidda Project, the Sardinian government will take the heavy economic burden to build the infrastructure (e.g., smart network upgrading, renewable energy, deployment, storage, home automation systems, and so on) that is the major barrier for self-financed renewable energy community projects.

The authors are quite conscious of the importance of the social acceptance of this kind of project, also when the cost to be sustained by the citizens is low or negligible. For instance, a similar experience of an energy community in Sardinia has been recently realized within the Interreg Med project STORES $[17,18]$ where the communities of five pilot sites in Italy, Portugal, Cyprus, Greece, and Slovenia, were involved in a voluntary participation to the studies for the development of an optimal policy for the effective integration of photovoltaics (PV) and ESS via testing smart solutions [18]. In particular, in the Sardinian municipality of Ussaramanna, 13 pilot sites were implemented in 13 private residential houses that received free ESS of various sizes. All citizens of the municipality were invited to a public meeting, and letters were also sent to communicate the possibility of joining the 
project. Only 13 users, already equipped or who have equipped themselves with a PV system, to take advantage of this opportunity, have joined the project; another user owning a photovoltaic system did not join because he thought that the storage system would create problems for his PV system, other citizens did not join due to their doubtful usefulness of ESS, due to lack of proper/sufficient information about safety issues, space requirements, and financial issues related to the reduction of feed-in tariffs applied to their PV systems.

The authors are definitely confident about the success of the Berchidda project, which owns all the features foreseen by the directives [12,13]:

- The distribution network is owned by the municipality, which can operate as a legal entity taking control of the network as distribution system operator and of the consumption of energy of the community participants/members (its citizens);

- All members of the community will participate voluntarily to take advantage of having renewable energy (e.g., mainly PV systems) at only the "cost" of making their rooftop available for the installation of the renewable generation system; given that the public investment will not be sufficient for installing new technologies for all the citizens of Berchidda, a selection criterion will be applied for the citizens in order to find the ones with bigger merit (socioeconomic status, energy consumption, existing photovoltaic system, sun exposition of the rooftop, and so on), with the primary objective purpose of providing environmental, economic, or social community benefits. No specific costs will be sustained by citizens, and no financial profits will be allocated to the municipality.

\section{3. "Berchidda Energy 4.0" Project}

\subsection{Current Situation}

Berchidda is an old village in the North East of Sardinia (Figure 1a) with some 5000 inhabitants (Figure 1b). Berchidda has a prosperous economy based on agriculture, wine production, cork, granite extraction, and tourism. Thanks to its millennial history, the people of Berchidda are proud of their own traditions, culture, and language (Sardinian language). The social cohesion and the community sense are well established, as well as the willingness to be the leader of the regional area and the lighthouse for the neighbor municipalities to follow. The relationship between people and territory is strong, and almost everyone in Berchidda is aware of the social and economic worth of the natural beauties of the area. On the other hand, because of the strong sense of community, the people of Berchidda do not like external interferences in any decision regarding the use of territory, including energy policy. For these reasons, the municipality of Berchidda holds the Azienda Elettrica Comunale (A.E.C., i.e., "Municipal Power Company"), which is the owner of the local MV/LV distribution network and holds the concession for delivering and selling electrical energy in its territory, operating like a distribution network operator (DNO). Despite the fact that municipal electric power companies are not common in Italy, and in Sardinia in particular (only 2 municipalities in a total of 377), the people of Berchidda decided to sustain the social and financial costs to own the distribution network and to be an independent energy community. The financial benefits for the community have been negligible so far, and since the price of energy is not cheaper than out of the community, the job opportunities related to AEC are limited to the few people working for the company and to the few contractors involved in corrective maintenance. The environmental benefits are negligible since no specific actions to buy energy produced by renewables have been taken. The sense of community and independence has so far been the only reason to hold the distribution network or, in other words, the social cohesion has been considered so important for overcoming social and financial costs. However, thanks to the former hard and expensive decisions, Berchidda now has the opportunity to apply EU directives on energy communities without waiting for the implementation in the national and regional legislation with significant economic, social, and environmental benefits. For this reason, both the Municipality of Berchidda and A.E.C. are engaged in the upgrading of the distribution network and in reinforcing 
the local RES-based energy production. The main planned actions are the acquisition of the rural electricity network, which includes $13 \mathrm{MV} / \mathrm{LV}$ substations, and was formerly owned by the Italian DSO e-distribuzione, and the modernization of the urban network. The first action has been recently completed, and a new rural network further increases PV and wind generation in the area. The second action, the modernization of the urban distribution network (Figure 2) and the establishment of the energy community, is the subject of the present study.

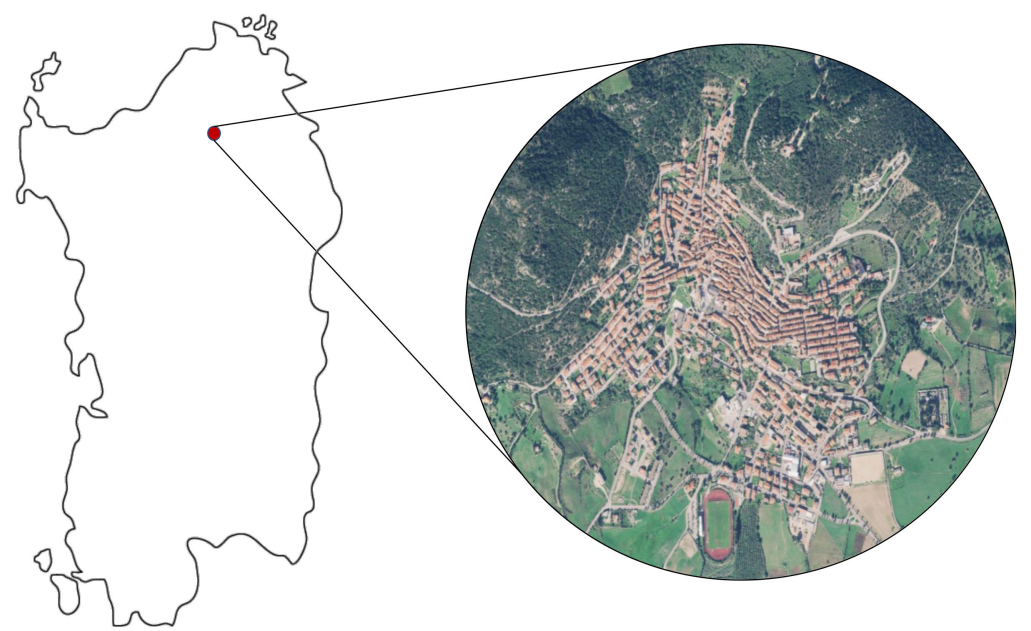

(a)

(b)

Figure 1. (a) Sardinia island. (b) Municipality of Berchidda-urban network.

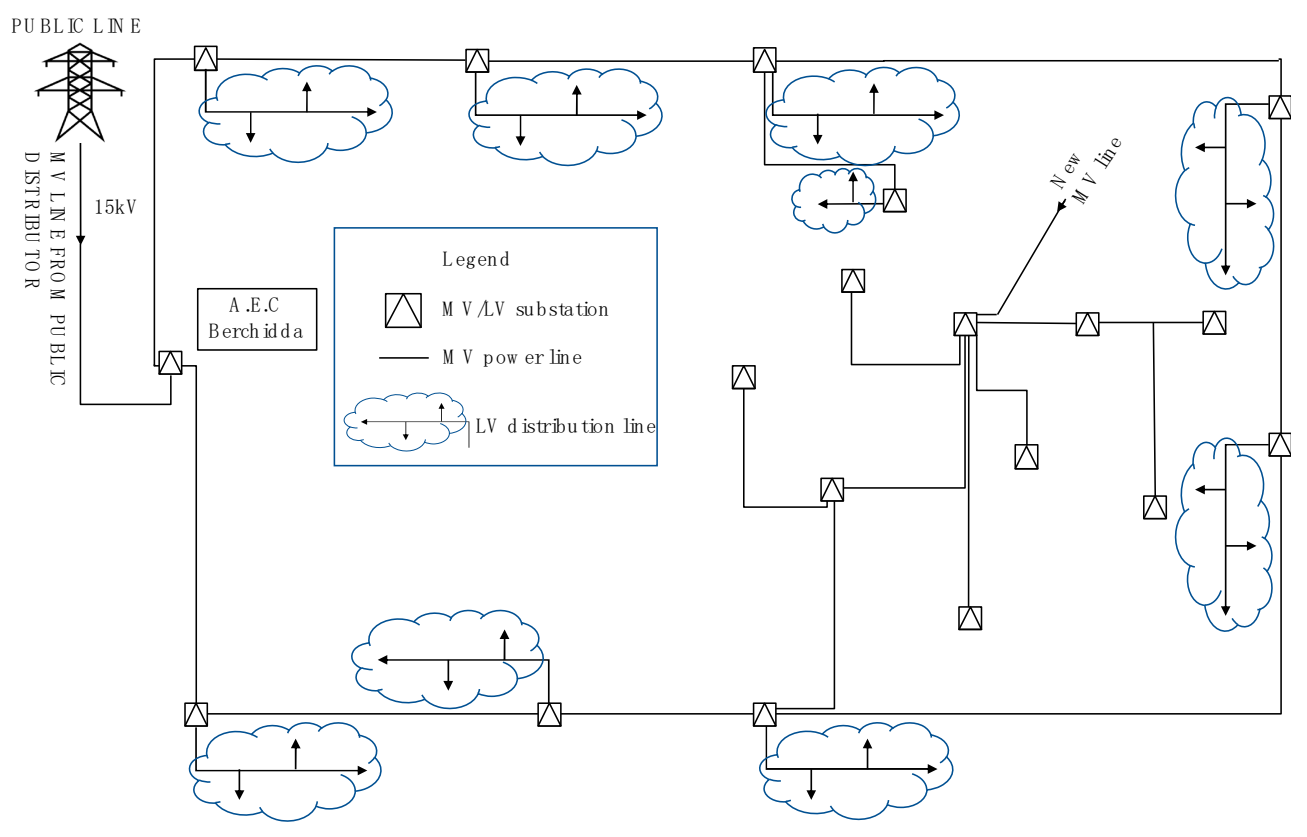

Figure 2. Urban power distribution network structure.

The main characteristics of the urban power grid are as follows:

- $\quad 18 \mathrm{MV} / \mathrm{LV}$ substations, which are equipped with transformers of varying power between $100 \mathrm{kVA}$ and $500 \mathrm{kVA}$, for a total power installed of about $5000 \mathrm{kVA}$;

- $\quad 4 \mathrm{~km}$ of MV underground cables, $3.2 \mathrm{~km}$ for the meshed network, and $0.8 \mathrm{~km}$ for the radial network;

- $\quad 15.4 \mathrm{~km}$ of LV aerial cables;

- $\quad 21.6 \mathrm{~km}$ of LV underground cables. 
In addition, the DSO A.E.C. only has one connection point (at MV level) with the upstream distribution network. This feature facilitates the energy exchange measurement between the A.E.C. and the distribution network managed by the distribution network operator e-distribuzione.

Table 2 shows the different types of users and the related energy purchased from the public grid.

Table 2. Berchidda customers types and related energy purchased from the public grid.

\begin{tabular}{ccccc}
\hline Customer Type & \# Customers & Voltage Level & Power Installed [kW] & Energy Consumed [MWh/y] \\
\hline Residential (household) & 1051 & LV & 3209 & 2761 \\
Public buildings & 259 & LV & 797 & 301 \\
Commercial \& Industrial & 292 & LV & 1666 & 2316 \\
MV consumers & 2 & MV & 346 & 269 \\
Public lighting & $/$ & LV & 246 & 414 \\
\hline Total & 1626 & $/$ & 6234 & 6061 \\
\hline
\end{tabular}

The average load profile of the Municipality of Berchidda is shown in Figure 3, distinguishing the gross load and the net load obtained considering the impact to the load curve of $67 \mathrm{PV}$ plants, owned by private citizens and companies, for $608 \mathrm{kWp}$ already installed.

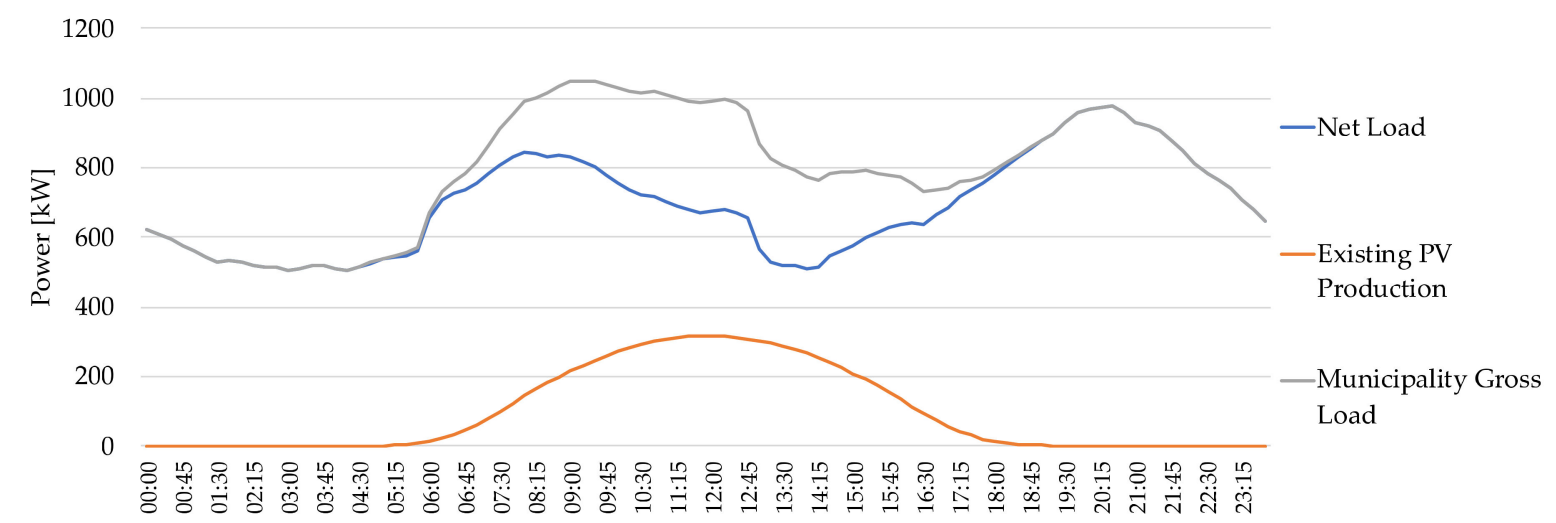

Figure 3. Current load profile and photovoltaic (PV) production in Berchidda urban network.

The area between the blue curve and the gray curve represents the energy produced by the existing local PV plants, which reduces the electric energy that needs to be bought for the needs of the whole community. The energy purchased/withdrawn from the grid is about $16.4 \mathrm{MWh} / \mathrm{d}$, and the mean daily gross electric load is approximately $19 \mathrm{MWh} / \mathrm{d}$, which amounts to $6.9 \mathrm{GWh} / \mathrm{y}$.

\subsection{Transition Towards a Smart Local Energy Community}

The development of the energy community of Berchidda will require cooperation among citizens and, in general, among public and private stakeholders finalized to reduce the energetic dependence from the public grid and minimize the energy bill by increasing the self-consumption of the energy produced with renewable sources. The crucial aspect for the transition towards a smart local community will be the development of an intelligent distribution network with a distribution energy management system (DMS/EMS) able to attain the best integration of energy production by renewable sources (mostly by photovoltaic plant), also with the exploitation of ESS, and the flexibility offered by the consumers, producers, and prosumers all equipped with smart home automation system for demand side participation (Figure 4). With the DMS/EMS, the LEC network operator will also be able to trade the overproduction of energy with others/pairs inside or outside the LEC, and provide ancillary services to the distribution/transmission system operators upstream of the distribution/transmission network feeding Berchidda's network. 


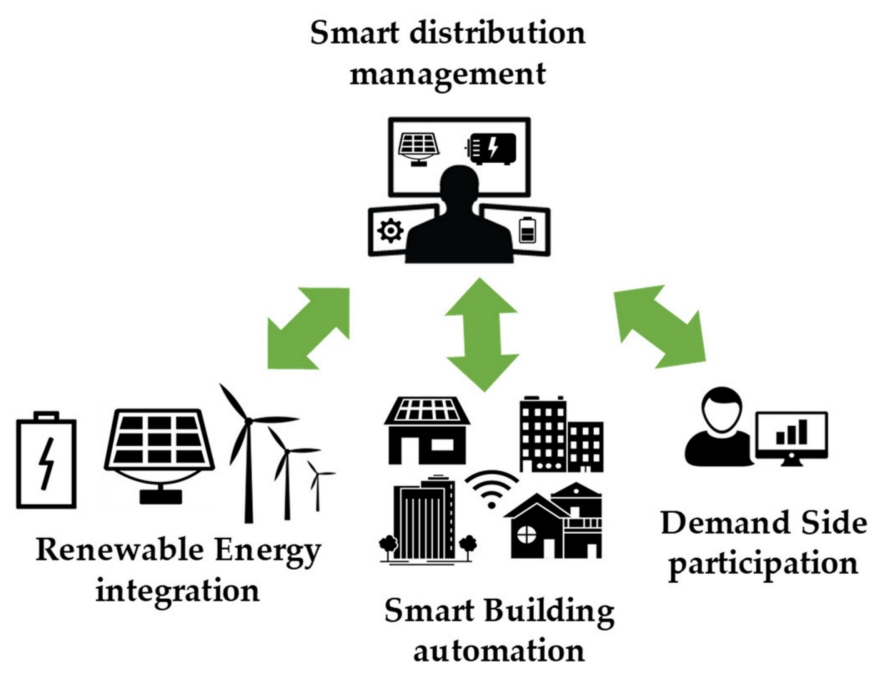

Figure 4. Smart distribution management of the local energy community resources.

This project proposes a complete implementation of the smart energy systems of the LEC that requires the involvement of users through the management of their active loads, also by incentivizing the replacement of existing appliances with equivalent smart appliances, as well the boosting of renewable energy production and storage systems intelligently managed by a local energy management system able to communicate and take actions under request from a hierarchical network energy management coordinator.

\subsection{Increasing of Energy Self-Consumption with Demand Response}

In order to increase the share of self-consumed energy, it is necessary to apply strategies of demand response (or load shifting). In the project, this consists of assuring that most of the consumptions occur during the day when PV plants are producing. This is the reason why the first action consists of equipping the citizens of Berchidda with smart meters (SM) for the real time consumption monitoring and for sending to the single user/prosumer messages and advice for efficient energy use. The SM will be used for gathering data from the field and to forecast the expected consumption. Day-ahead and short-term demand predictions will be combined with weather forecasts for the prediction of energy production. The EMS software will predict the optimal consumption plan for each customer and send it to each customer by using an app running on mobile phones, computers, and tablets. The customer will be aware of the optimal consumption plan and will be able to decide to accept it or not. In particular, each customer will be informed about the optimal time to use his/her household appliances and about the impact of his choice on the energy bill of the community and the decision of neighbors and other customers that have a similar energy use, number of appliances, level of education, annual income, or annual energy consumption. The goal is to foster the engagement of people and to increase the level of participation with APP in smartphones, tablets, and computers, and the creation of social platforms to create a bottom-up process of involvement have been assumed in this proposal. Thanks to these actions, a load-shifting of $20 \%$ (almost $800 \mathrm{kWh} / \mathrm{d}$ ) from evening hours to day-time PV production hours is expected. Furthermore, as demonstrated in [19], if customers are aware of their energy consumption, the final residential users (which are $50 \%$ of the total Berchidda's load) spontaneously reduce their demand up to about $8 \%$ equally distributed during the day.

Figure 5 shows the impact on expected load demand after the application of demand response policies. The measured average load has been shifted in order to consider the expected reduction of $700 \mathrm{kWh} / \mathrm{d}$ (represented by the area between the blue curve and the gray curve in Figure 5, which shows the expected load profile resulting from this action, corresponding to about $255 \mathrm{MWh} / \mathrm{y}$, or $4 \%$ of the total annual consumption). Furthermore, the shape of load demand is also modified by the demand response with a significant quota of consumption coincident with the photovoltaic production. 


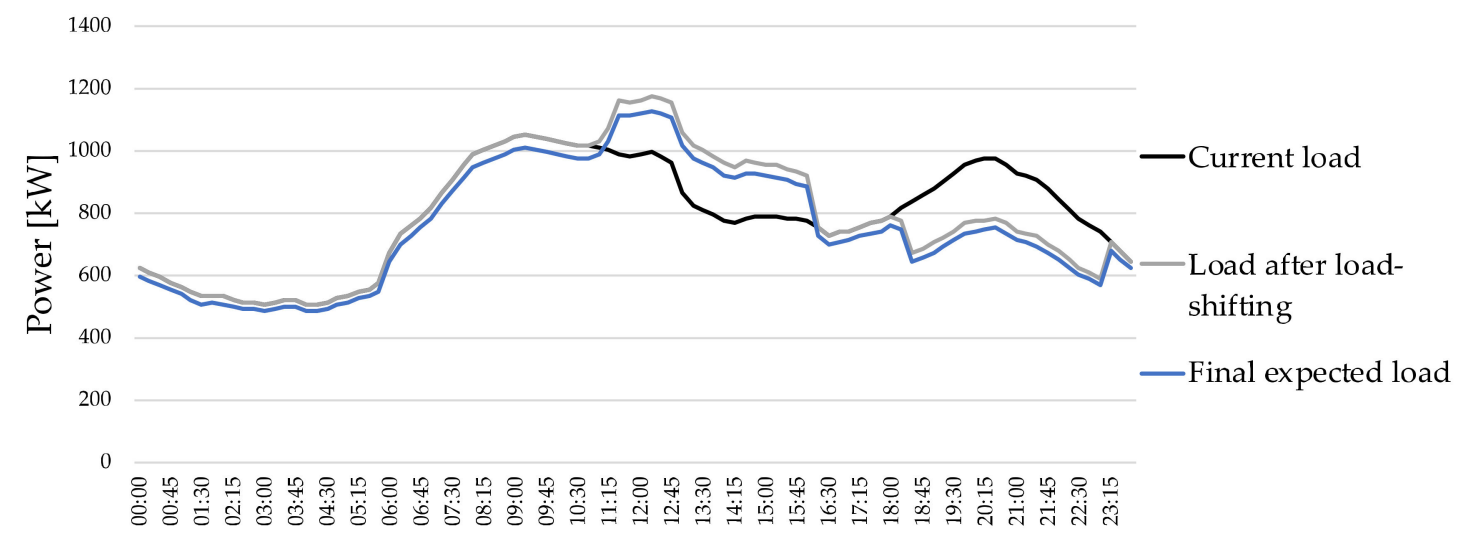

Figure 5. Load-shifting effect on demand.

\subsection{Energy Production with Renewable Energy Sources and Storage Support}

The optimal sizing of generation and storage for the LEC has been found with the support of the software HOMER, a simulation tool developed by the National Renewable Energy Laboratory (NREL) [20]. An equivalent model of microgrid has been created in HOMER considering the load of the LEC and the energy management system (EMS) for the coordination of the energy resources (load/generation/storage) and is capable of permitting LEC exchanging power with the upstream distribution network. By considering technical and economic aspects, an hourly time series simulation of the system operation over a year has been performed. According to the study, and taking into account the economic budget, the best configuration for the Berchidda's LEC is with $1500 \mathrm{kWp}$ of PV plants (besides the $608 \mathrm{kWp}$ already installed) on the rooftops of both private and public buildings. The number of the rooftops will depend on the citizens' interest in the project, and a variable number of 200-230 small PV systems (for residential, commercial, and public buildings with sizes ranging from $3 \mathrm{kWp}$ to $20 \mathrm{kWp}$ ) is expected. The current and expected total PV production are summarized in Table 3.

Table 3. Actual and future PV power plants in the Berchidda distribution network.

\begin{tabular}{cccc}
\hline PV Capacity & Number of PV Plants & Power [kWp] & Energy [kWh/y] \\
\hline Existing PV plants & 67 & 608 & 820,000 \\
New PV plants & $\approx 200-230$ & 1500 & $2,000,000$ \\
\hline Total & $\approx 300$ & 2108 & $2,820,000$ \\
\hline
\end{tabular}

In order to support the operation of the PV system, 30 small Li-Ion ESS (3 kW/10 kWh) will be installed at the consumer's premises. Those distributed ESSs, suitably coordinated by the central EMS and the local energy management systems at user location (EMU), compensate the power fluctuations caused by RES production's variability and retrieves the energy that cannot be used instantaneously, with the purpose of maximizing the self-consumption and minimizing the energy purchased from the main grid for the single user. A detailed analysis of a single user permits showing the behavior of the energy management system at the user location (EMU) in the management of the storage. The smart energy system of the residential power system optimizes the charging/discharging profile of the storage system as shown in [21,22] with greater detail. Furthermore, another four $50 \mathrm{~kW} / 50 \mathrm{kWh}$ ESS are planned to be positioned in $4 \mathrm{MV} / \mathrm{LV}$ substations, with the aim of smoothing the load curve of the local public network.

The transformation of the LV distribution network is sketched in Figure 6. The impact of the combination of the citizen's involvement and the exploitation of the RES on the single energy home area network (HAN) are schematically depicted in Figure 7. 

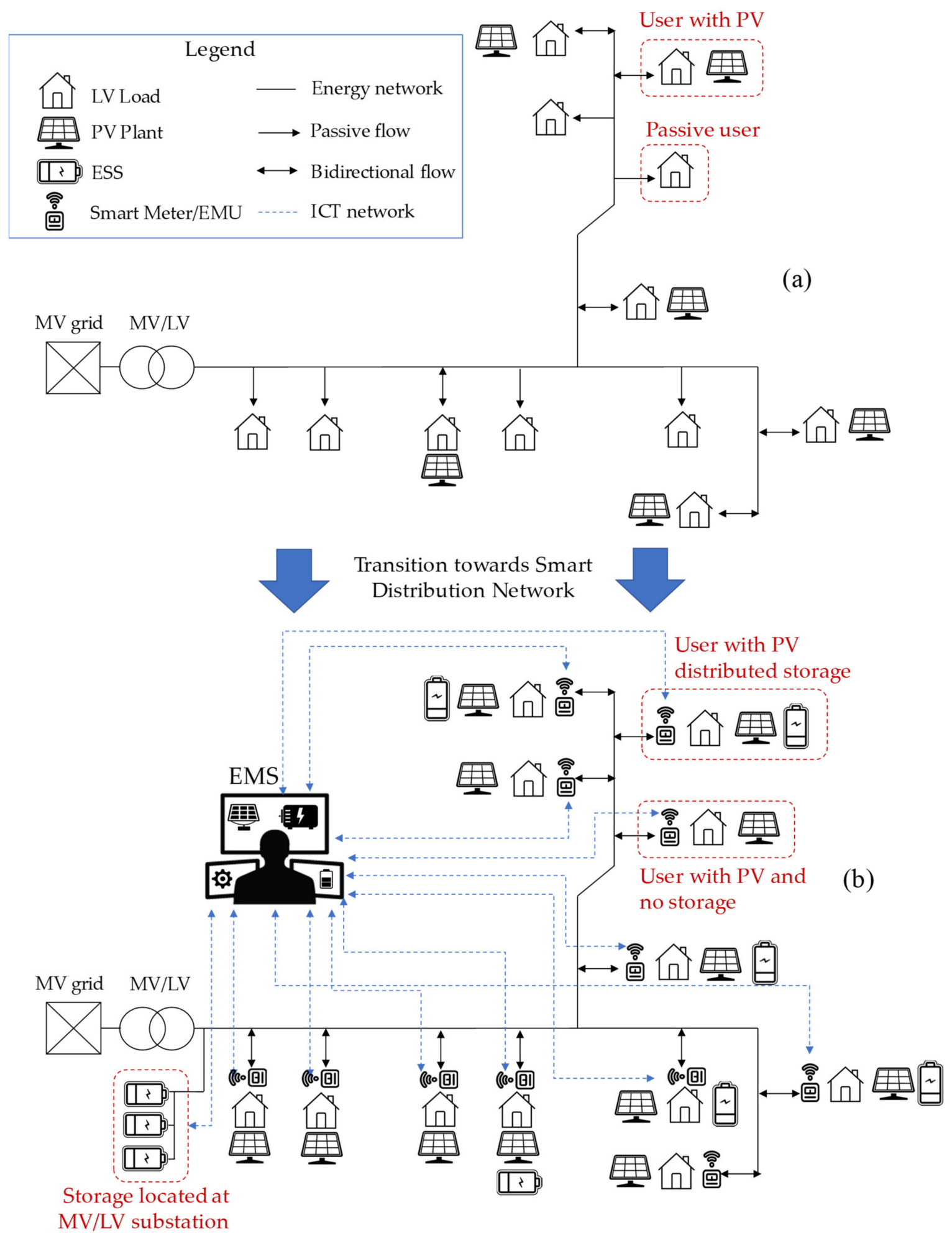

Figure 6. (a) Present LV distribution network. (b) Future LV distribution network. 


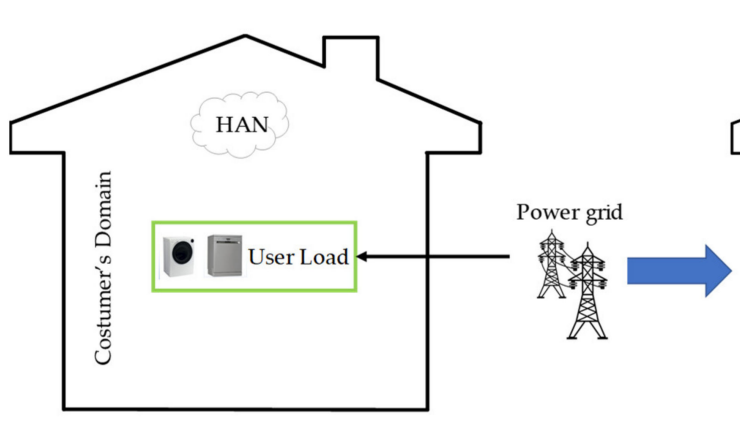

(a)

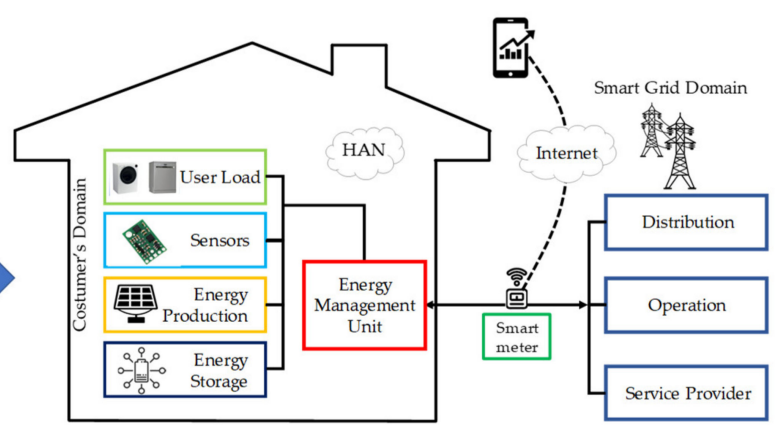

(b)

Figure 7. (a) Present energy home area network (HAN) structure; (b) Future energy HAN structure.

Figure 8 shows the variations of the daily energy exchanges with the network for a typical residential load. In the current situation (Figure 8a), the consumer only absorbs energy with a clear evening peak. The expected profile (Figure $8 b$ ) is characterized by the presence of bidirectional power flows since, in the daylight hours, the installed PV is capable of injecting energy into the system. The use of PV and ESS allows for reducing the energy withdrawn from the local community network; the ESS increases the self-consumption, and the EMU optimizes the charge and discharge cycles depending on the actual price of energy, the charge status of the ESS and the actual load/production. The energy that cannot be either used instantly nor stored is injected into the network.
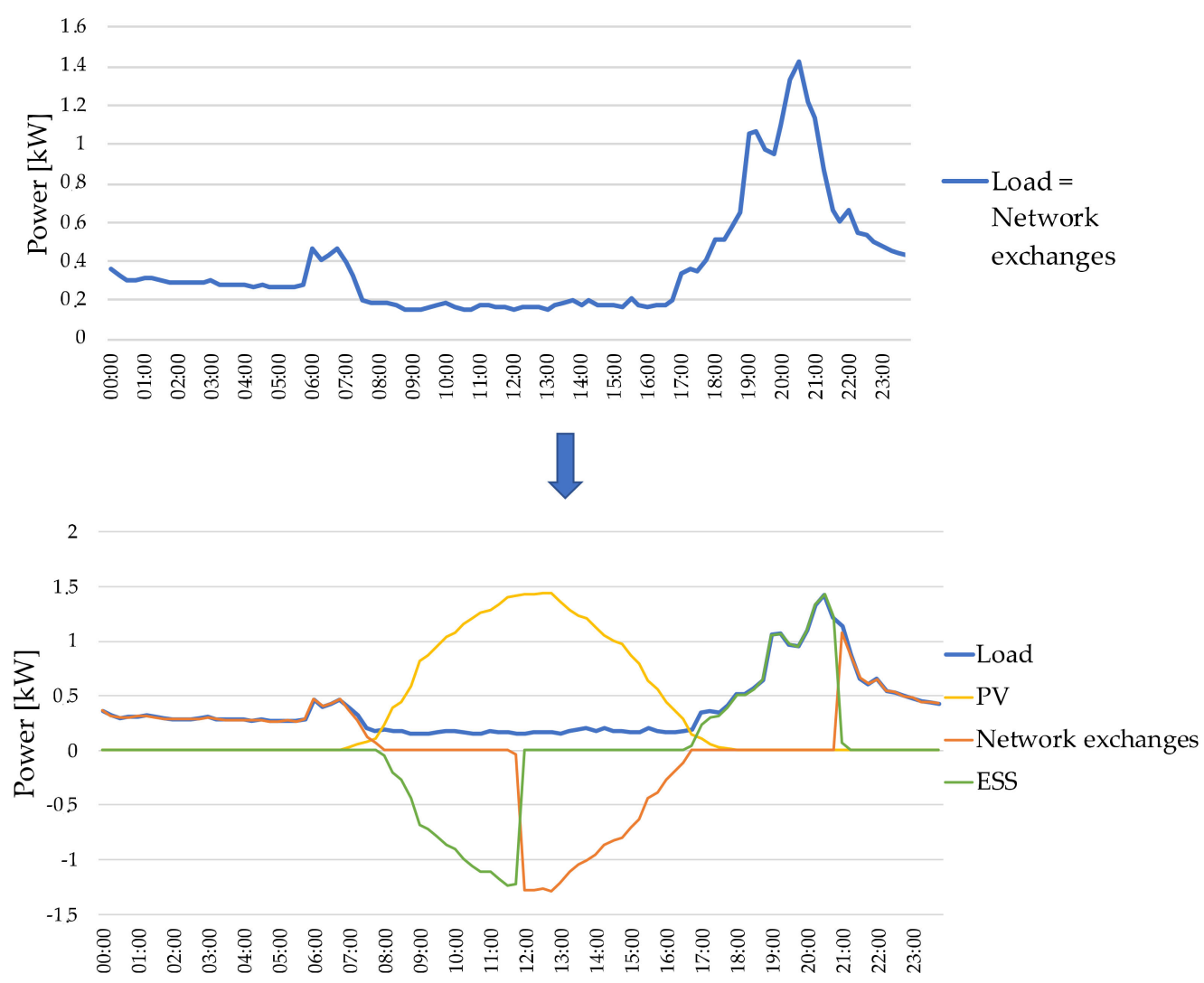

(b)

Figure 8. (a) Present network exchanges; (b) future network exchanges.

\subsection{Deployment of New Energy Carrier}

Although Sardinia does not have a natural gas distribution infrastructure yet, gas can be imported from the mainland in the form of LNG. This energy vector enables the use of available technologies, such as fuel cells and microturbine plants in Combined Heat and Power (CHP) configuration. The installation 
of one dispatchable plant of $200 \mathrm{kWe}$ is planned to be used near users with a high heat demand for both residential and industrial purposes.

There are several reasons to use CHP and gas in the LEC. In the short term, the CHP will enable a significant cut on the energy bill of the community since local production might be more convenient for purchasing energy. In the long term, the community will have the power facilities that can be combined with more innovative storage systems, such as the Power-to-Gas system that will enable higher penetration of renewable energy sources in the LEC.

\subsection{LEC Planned Load Profile at the Point of Common Coupling with the Upstream Distribution Network}

By combining the contribution of the load shifting and of the improved energy efficiency, the effect of the new PV, ESS, and CHP, the expected LEC's load profile measured at the point of connection with the upstream network, will be like that of the orange curve in Figure 9.

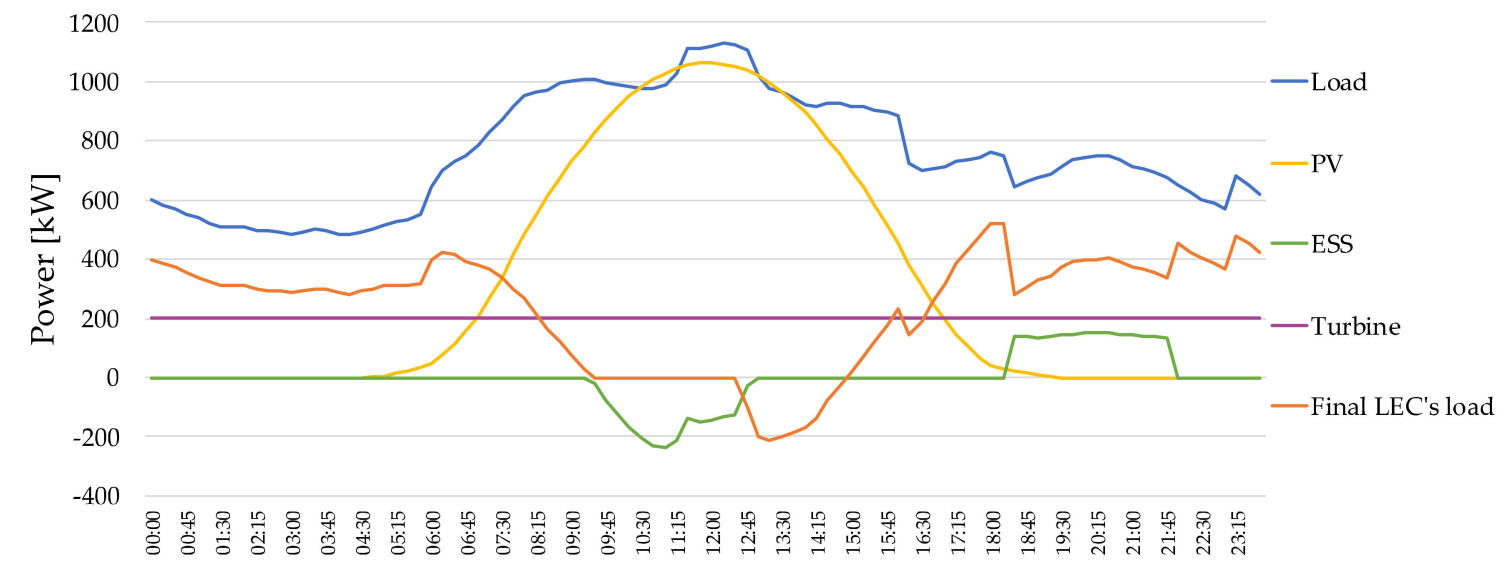

Figure 9. Final daily LEC's load profile.

The energy purchased by the LEC can be reduced by more than $66 \%$, from $16,400 \mathrm{kWh} / \mathrm{d}$ to $5600 \mathrm{kWh} / \mathrm{d}$, and the self-consumption of locally produced energy will be close to $95 \%$. The share of each technology/action that will be implemented with reference to the contribution to the reduction of energy purchased from the main grid is summarized in Table 4.

Table 4. Project effects on the energy purchases.

\begin{tabular}{cc}
\hline Smart Grid Action & Expected Reduction of Energy Purchases from the Grid \\
\hline PV and Storage & $-30 \%$ \\
Demand/Response \& Smart Metering & $-4 \%$ \\
CHP Plant & $-28 \%$ \\
Network Losses & $-4 \%$ \\
\hline
\end{tabular}

\subsection{Smart Grid Infrastructure}

The development of the future energy system of Berchidda in accordance with the smart grid paradigm requires a radical change in the management of the electricity distribution network, which needs to become intelligent and adaptive, with the deployment of systems able to control a combination of distributed energy resources (DERs). The electric system will be managed and controlled through a communication network, which will allow a bidirectional exchange from and to customers and local producers.

The MV/LV secondary substations will be transformed into smart secondary substations with a pervasive use of digital communication and intelligent electronic devices (IEDs) and remote terminal units (RTU) to enable local and/or remote sensing and control of substation equipment, as well smart meters (SM) of the active users of the network (Figure 10). The distribution management system 
(DMS) infrastructure will be able to manage energy flows, contribute to voltage regulation, ensure fast reconfiguration after a failure, and identify and pursue efficiency opportunities (e.g., network reconfiguration for losses reduction).

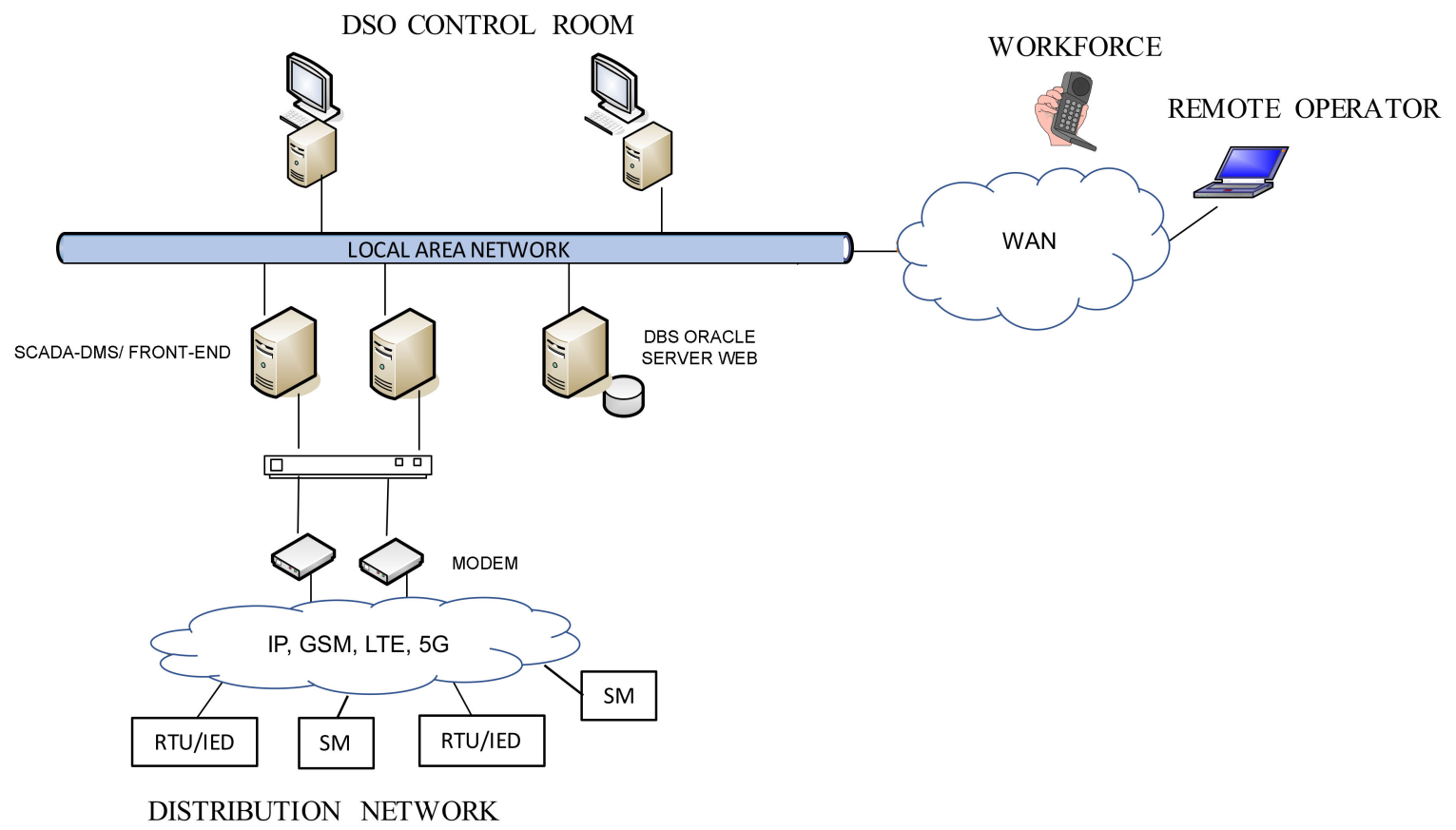

Figure 10. Future LEC smart grid infrastructure.

The future smart grid, with the SCADA system described above, will be able to manage all the expected PV production plants and would be implemented, among other functions, the self-healing function for automatic fault management and remote network reconfiguration, also allowing the closed loop management of the distribution system.

\subsection{Economic Analysis of the Smart Grid Actions}

The energy cost allocation for A.E.C. is shown in Table 5. The cost of energy purchasing is $1.342 \mathrm{M} € / \mathrm{y}$, and the implementation of the planned actions will reduce such expenses significantly.

Table 5. Energy costs allocation.

\begin{tabular}{ccc}
\hline Tariff Component & Current Amount $[\mathbf{\epsilon} / \mathbf{y}]$ & Expected Amount $[\mathbf{\epsilon} / \mathbf{y}]$ \\
\hline Energy & 632,000 & 215,000 \\
Transmission \& Metering & 239,000 & 81,000 \\
System charges & 471,000 & 376,000 \\
\hline Total & $1,342,000$ & 672,000 \\
\hline
\end{tabular}

In particular, since the quantity of purchased energy will decrease by $66 \%$, not only the expenses for energy but also the fees for the usage of the transmission system and for metering will decrease accordingly. Although the system charges consider some fixed charges that cannot be removed, the new smart energy infrastructure will lead to economic savings for the LEC's final users, which are expected to be more than $20 \%$ of the total electricity costs.

\section{Conclusions}

The paper describes a planning study for transforming the Power Company of the Municipality of Berchidda (Italy) into an energy community able to facilitate the exchange among citizens of the energy 
generated from renewable sources, as well as improving efficiency and reducing energy consumption from the public network.

The project concerns fostering renewable energy plants and revamping the municipal distribution network as a smart grid. The demand response is used for optimizing the energy consumption and increasing the coincidence with the solar production; the energy storage is designed to boost self-consumption of solar PV production; the CHP is used to partially cover the base load in a more convenient way.

The results of the study predict the reduction of the energy purchased from the main grid leading to significant economic savings, as well as environmental benefits for the LEC's final users and the improvement of the quality and continuity of service.

Author Contributions: E.G., F.P., and L.R. conceived the idea behind this research and wrote the paper, A.G. designed the simulations and wrote the paper; A.N. is responsible for the acquisition of the financial support for the project leading to this publication. All the authors analyzed the data and proofread the paper.

Funding: "This research was funded by the Municipality of Berchidda. Development and Cohesion Fund 2014-2020. Pact for the development of the Region Sardinia. Action line 1.6.2-Transformation of the Sardinian Energy System towards an integrated and intelligent configuration (Sardinian Smart Energy System)". This research work has also been supported by the Sardinia Region within the projects "SEC-Smart Energy Community", funded under the call "Research and development program in Smart Networks for Efficient Energy Management" and "SMARTPOLYGEN-Development of Smart Polyenenergetic Microgrids" under the call "Cluster Top-Down Projects"- POR FESR 2014-2020.

Conflicts of Interest: The authors declare no conflict of interest.

\section{References}

1. Ghiani, E.; Serpi, A.; Pilloni, V.; Sias, G.; Simone, M.; Marcialis, G.; Pegoraro, P.A. A Multidisciplinary Approach for the Development of Smart Distribution Networks. Energies 2018, 11, 2530. [CrossRef]

2. Tuballa, M.L.; Abundo, M.L. A review of the development of Smart Grid technologies. Renew. Sustain. Energy Rev. 2016, 59, 710-725. [CrossRef]

3. Kazmi, S.A.; Shahzad, M.K.; Khan, A.Z.; Shin, D.R. Smart Distribution Networks: A Review of Modern Distribution Concepts from a Planning Perspective. Energies 2017, 10, 501. [CrossRef]

4. Pilo, F.; Celli, G.; Ghiani, E.; Soma, G.G. New electricity distribution network planning approaches for integrating renewable: New electricity distribution network planning approaches for integrating renewable. Wiley Interdiscip. Rev. Energy Environ. 2013, 2, 140-157. [CrossRef]

5. De Zotti, G.; Pourmousavi, S.A.; Madsen, H.; Poulsen, N.K. Ancillary Services 4.0: A Top-to-Bottom Control-Based Approach for Solving Ancillary Services Problems in Smart Grids. IEEE Access 2018, 6, 11694-11706. [CrossRef]

6. Shayeghi, H.; Shahryari, E.; Moradzadeh, M.; Siano, P. A Survey on Microgrid Energy Management Considering Flexible Energy Sources. Energies 2019, 12, 2156. [CrossRef]

7. Gui, E.M.; Diesendorf, M.; MacGill, I. Distributed energy infrastructure paradigm: Community microgrids in a new institutional economics context. Renew. Sustain. Energy Rev. 2017, 72, 1355-1365. [CrossRef]

8. Walker, G.; Devine-Wright, P. Community renewable energy: What should it mean? Energy Policy 2008, 36, 497-500. [CrossRef]

9. Rae, C.; Bradley, F. Energy autonomy in sustainable communities-A review of key issues. Renew. Sustain. Energy Rev. 2012, 16, 6497-6506. [CrossRef]

10. Van Der Schoor, T.; Scholtens, B. Power to the people: Local community initiatives and the transition to sustainable energy. Renew. Sustain. Energy Rev. 2015, 43, 666-675. [CrossRef]

11. Clean Energy for All Europeans. Energy-European Commission, 20-ott-2017. Available online: https: //ec.europa.eu/energy/en/topics/energy-strategy-and-energy-union/clean-energy-all-europeans (accessed on 21 August 2019).

12. European Union. Directive (EU) 2018/2001 of the European Parliament and of the Council-Of 11 December 2018-On the Promotion of the Use of Energy from Renewable Sources; European Union: Brussels, Belgium, 2018. 
13. European Union. Directive (EU) 2019/944 of the European Parliament and of the Council of 5 June 2019-on Common Rules for the Internal Market for Electricity and Amending Directive 2012/27/EU; European Union: Brussels, Belgium, 2019.

14. Frieden, D.; Tuerk, A.; Roberts, J.; D'Hebermont, S.; Gubina, A. Collective Self-Consumption and Energy Communities: Overview of Emerging Regulatory Approaches in Europe. Working Paper, June 2019. Available online: https://www.compile-project.eu/wp-content/uploads/Explanatory-note-on-energycommunity-definitions.pdf (accessed on 21 August 2019).

15. Kalkbrenner, B.J.; Roosen, J. Citizens' willingness to participate in local renewable energy projects: The role of community and trust in Germany. Energy Res. Soc. Sci. 2016, 13, 60-70. [CrossRef]

16. Seidl, R.; Von Wirth, T.; Krütli, P. Social acceptance of distributed energy systems in Swiss, German, and Austrian energy transitions. Energy Res. Soc. Sci. 2019, 54, 117-128. [CrossRef]

17. Afxentis, S.; Florides, M.; Yianni, C.; Efthymiou, V.; Papageorgiou, I.; Partasides, G.; Oliveira, J. Promotion of higher penetration of distributed PV through storage for all (StoRES). In Proceedings of the International Congress on Engineering and Sustainability in the XXI Century, Faro, Portugal, 11-13 October 2017.

18. STORES Project. Available online: https://stores.interreg-med.eu/ (accessed on 21 August 2019).

19. ADDRESS Project-FP7 ENERGY. Available online: http://www.addressfp7.org/ (accessed on 21 August 2019).

20. Lambert, T.; Gilman, P.; Lilienthal, P. Micropower System Modeling with Homer. In Integration of Alternative Sources of Energy; Farret, F.A., Simões, M.G., Eds.; John Wiley \& Sons: Hoboken, NJ, USA, 2005; pp. $379-418$. [CrossRef]

21. Ghiani, E.; Garau, M.; Celli, G.; Pilo, F.; Marongiu, G. Smart integration and aggregation of nanogrids: Benefits for users and DSO. In Proceedings of the 2017 IEEE Manchester PowerTech, Manchester, UK, 18-22 June 2017; pp. 1-6.

22. Garau, M.; Ghiani, E.; Celli, G.; Pilo, F. Tecno-economic and environmental assessment of a full electric smart city eco-district. In Proceedings of the 2017 AEIT International Annual Conference, Cagliari, Italy, 20-22 September 2017; pp. 1-6.

(C) 2019 by the authors. Licensee MDPI, Basel, Switzerland. This article is an open access article distributed under the terms and conditions of the Creative Commons Attribution (CC BY) license (http://creativecommons.org/licenses/by/4.0/). 